\title{
Sensitising Dyes and their Use in Scientific Photography*
}

\author{
By Dr. C. E. K. Mees
}

$\mathrm{O}^{\mathrm{N}}$ NE of the problems to be encountered in the early days of photography was that photographic materials were not sensitive to the spectrum in the same way that the eye is. Whereas the normal eye is sensitive to the colours of the spectrum from violet through blue, green, yellow and orange to red, the early photographic plates were sensitive only to the ultra-violet, violet and blue.

In 1873, H. Vogel, of Berlin, found that some collodion dry plates possessed sensitivity in the green portion of the spectrum, and he traced this green sensitivity to the presence in the emulsion of a yellow-red dye. Vogel got similar effects with other dyes which, on this account, were later called sensitising dyes or sensitisers, and he came to the conclusion that when a dye acted as a sensitiser in this way, the region of the spectrum for which it was effective corresponded approximately to the absorption band of the dye. Thus a dye which absorbed green light would render a photographic plate sensitive to green. This fundamental relationship underlies all work on sensitising, and it is worthy of attention that Vogel grasped this truth immediately in spite of the fact that his emulsions were very slow, his dyes probably impure and, at best, weak sensitisers, and his apparatus primitive.

Vogel recognised that the dyes which acted as sensitisers for silver bromide must not merely stain the collodion or gelatine in which the silver bromide was imbedded but must also actually be adsorbed on to the surface of the silver bromide particles. Thus the energy which they absorbed could be transmitted in some way to the silver bromide. Vogel's results were at first subjected to a great deal of adverse criticism, and even ridicule, many other workers being unable to confirm his results. But Becquerel in 1874, and then Water. house in 1875, were able to support his discovery.

The first sensitising dye to attain any general use was eosin, which sensitises collodion emulsion strongly for the yellow-green. After the introduction of gelatine dry plates, J. M. Eder suggested the use of erythrosin in the place of eosin, and this was generally adopted for the production of the so-called 'orthochromatic' plates, and was almost the only dye used in commercial manufacture before 1906 .

Shortly after the beginning of this century, attention was directed to the dyes belonging to

- Friday Evening Discourse delivered at the Royal Institution on January 31. the 'cyanine' group. In 1856, a dye known as 'cyanine' had been made by Williams from impure quinoline, but although it had a beautiful blue colour, it was very fugitive to light. Williams's cyanine had been used by Vogel in his early experiments and was considered a useful sensitiser for the orange-red, but it caused fog and spotty patches on the plates.

In 1883, another dye made from quinoline and related to cyanine was discovered, and in 1902 this dye, known as 'ethyl red', was tested by Miethe and Traube for sensitising power, and was found to give good green sensitivity without the tendency to fog characteristic of cyanine. Ethyl red belongs to a group of dyes known as the isocyanines, which are synthesised by the treat. ment of a mixture of quinaldine and quinoline quaternary salts with an alkali.

At the time that Miethe and Traube described the sensitising power of the simple isocyanine, ethyl red, E. König of the Hoechst Works of Meister, Lucius and Brüning, was synthesising a number of iso-cyanines, which were placed on the market under trade names, such as Pinachrome, Orthochrome $T$, Pinaverdol, etc., these being made from substituted quinolines and quinaldines, and by 1904 it was clear that the eyanine dyes of the new type were much more suitable for use in photographic sensitising, especially for the yellowgreen and orange, than any dyes previously known.

In 1904 Homolka, one of König's colleagues, carried out the reaction used in the preparation of an isocyanine but with the addition of formaldehyde, and in the place of a red isocyanine he obtained a blue dye of which the structure was not elucidated at the time, but which proved to be a powerful sensitiser for the red, and was placed on the market under the name of Pina. cyanol. It was later found that the quinoline nucleus does not form part of the dye molecule, and pinacyanol is at present made from the quinaldine salts using a compound such as iodoform or orthoformic ester, to supply the additional methine group.

Soon after the discovery of pinacyanol, the little firm of Wratten and Wainwright in Croydon applied the new dyes, especially pinachrome and pinacyanol, to the preparation of commercial plates, and in 1906 made plates containing both pinachrome and pinacyanol, which were placed on the market under the name of 'Wratten 
Panchromatic' plates. These were the first panchromatic plates to be made on a commercial scale with the new type of dyes, and following the introduction of the plates and of a series of light filters adapted for use with them, the whole art of the photography of coloured objects developed rapidly as a practical commercial process.

The cyanine dyes are derived from organic bases containing nitrogen. Bases of this kind add on two atoms or groups to form quatemary salts. Thus quinoline adds on ethyl iodide and forms quinoline ethiodide. The bases from which the first cyanine dyes were derived were quinoline and quinaldine, in which the hydrogen attached to the carbon atom of quinoline next to the nitrogen has been replaced by a methyl group.

Our present knowledge of the structure of the cyanine dyes is due very largely to the work of Dr. W. H. Mills and his students at Cambridge, and of especial importance was the paper that he published with Dr. F. M. Hamer in 1920, on the structure of pinacyanol.<smiles>[3H]I1N=C(C=CC=C2C=Cc3ccccc3N2CC)C=Cc2ccccc21</smiles>

It will be seen that the two nitrogen atoms in the quinoline nuclei are connected by a chain of five carbon atoms with alternate double and single bonds between them. A system of this kind is known as a conjugate chain and is characteristic of the cyanine dye series.

Since the dyes in which one $\mathrm{CH}$ group derived from the base itself united the two nuclei are called cyanines, Mills and Pope called the dyes with three CH's in the chain carbocyanines, because it was necessary to supply one additional carbon atom. Later, Heilbron and his students at Liverpool made dyes with five CH's in the chain, and these he called dicarbocyanines. Very important dyes have been made containing seven CH's which are known as tricarbocyanines, while, as will be seen later, tetra- and pentacarbocyanines have been prepared with chains having nine and eleven $\mathrm{CH}$ 's respectively.

It will be realised that there must be an enormous number of cyanine dyes, because we not only have the possibility of varying the number of CH's in the chain, but also we can substitute a hydrogen in the chain by another group, and we can prepare dyes from a great many different organic bases containing nitrogen.

More than fifty years ago, Hofmann made a violet dye from the quaternary salt of 1-methyl benzthiazole, and Hofmann's dye was shown by Mills to be a thiacarbocyanine, the exact analogue of pinacyanol.

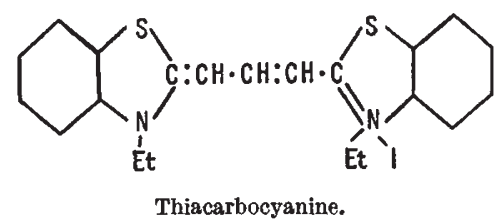

A very large number of dyes has now been made from substituted benzthiazoles, and many of these are excellent sensitisers.

The development of these new carbocyanines has during the last few years been of the greatest value for practical photography. The new dyes from the thiazole bases are far better sensitisers than pinacyanol and the other dyes derived from quinoline, and by making use of them new panchromatic materials have been prepared which are generally known as 'super-sensitive' or 'hypersensitive' materials.

The great value of these new sensitisers is that they do not lower the general sensitivity of the emulsion, and that they show no tendency to fog, emulsions sensitised with them often being even less prone to fog than the unsensitised emulsions. As a result, the effective sensitivity of the new panchromatic materials is greater than that of the same emulsions unsensitised, and this is particularly true when the emulsion is of very fine grain and is consequently slow before sensitising, and where the exposures are made to a light source rich in the red and green rays of the spectrum. Just at the time that the new sensitisers became available, the motion picture industry adopted the use of filament lamps for the greater part of studio lighting in place of the arc lamps used previously. The filament lamps are more convenient in operation because they need much less attention and they have the advantage of being entirely silent, which was necessary when soundrecording was added to the studio problems. But, nevertheless, it is doubtful whether the filament lamps could have been used had it not been for the great increase in the sensitivity to yellow light which was available from the application of the new sensitisers. The very great change which has occurred in the methods used in the making of motion pictures is, therefore, directly traceable to the scientific work on the structure of the cyanine dyes which $I$ have been discussing. In the same way, the use of panchromatic materials, and especially of panchromatic materials of exceptionally fine grain, stimulated the use of miniature cameras, and notably the use of those miniature cameras for photography indoors by artificial light which is often referred to as the use of the 'candid 
camera', perhaps because the results are sometimes more candid than pleasing.

The introduction of the new panchromatic materials, therefore, marks a real event in the history of photography, and I think that it is probable that the years 1928-30 may be regarded as beginning a new period in photography dating from the introduction of panchromatic materials into everyday use as distinguished from their previous employment for the specific photography of coloured objects. For the scientific applications of photography, however, the increase of sensitivity obtained in the visible spectrum, while of value, was less significant. The effective sensitiveness of the new panchromatic materials, as compared with those available previously, may be three or four times, and this is of the greatest importance in motion picture work; but it is not sufficient to make any great change in the practice of astronomical or spectroscopic photography. A much more important matter was the development of sensitisers specifically adapted to use in the infra-red region of the spectrum.

The first sensitiser to give satisfactory results in the infra-red was dicyanine, which was made at Hoechst in 1906. This dye was a true sensitiser for the near infra-red, but it was very unsatisfactory in use, and although it enabled the photography of the infra-red spectrum to be carried out, it was only used by a few workers who had acquired the necessary skill, and it was not practicable to make ready-sensitised plates with it. In 1919 Adams and Haller, working at the United States Bureau of Chemistry, carried out the pinacyanol reaction, but instead of using quinaldine in which the methyl group is on the carbon next to the nitrogen, they used lepidine, which is identical with quinaldine except that the methyl group is removed from the nitrogen, being separated by another two carbon atoms. The synthesis occurs quite normally and yields a blue-green dye which Adams and Haller called kryptocyanine.

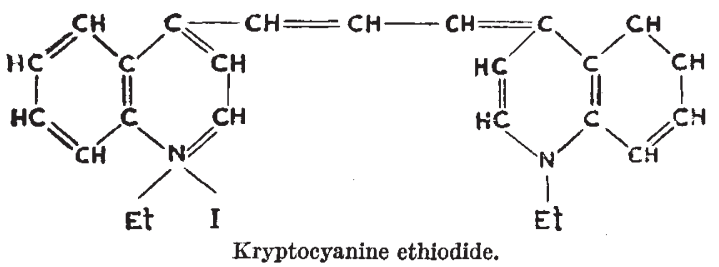

It will be seen that it is a carbocyanine like pinacyanol, but that in addition to the three CH's of the chain the nitrogen atoms are separated by three carbon atoms in each nucleus, so that the conjugate chain of kryptocyanine has four more links than that of pinacyanol. As we should expect, this shifts the absorption of kryptocyanine, and also its sensitising, towards the longer wave- length, so that its maximum of sensitivity is in the near infra-red at $\lambda 7500 \mathrm{~A}$.

Kryptocyanine is a very strong sensitiser, and by its use it was at once possible to take ordinary photographs using infra-red light. So long ago as 1910, Prof. R. W. Wood took photographs by light of longer wave-length than $\lambda 7000 \mathrm{~A}$., using a strong filter to cut out all the shorter wavelengths, and plates sensitised with pinacyanol; in these photographs the notable peculiarities of landscape pictures taken by infra-red light were manifest. The blue sky is almost black owing to the low scattering power of the upper atmosphere for the longer wave-lengths; clouds stand out in startling contrast to the black sky, and the chloro. phyll of grass and trees reflects the infra-red so that foliage appears as if it was covered with snow. Moreover, because of the low scattering power of the atmosphere for the longer waves, pictures taken by infra-red light show a penetration of the distance greatly exceeding that shown by ordinary photographs or even that visible to the eye. For Wood's pictures, the average time of exposure was approximately five minutes, but with kryptocyanine, an exposure of a fraction of a second was sufficient.

When preparing kryptocyanine in our laboratory in Rochester, H. T. Clarke found that the solution contained another dye which we named neocyanine, and which we now know to be of rather complicated structure, although it is still a cyanine dye. With this dye the maximum sensitivity was at $\lambda 8500 \mathrm{~A}$., and by means of it the photography of the spectrum was extended easily as far as $\lambda .9000 \mathrm{~A}$.

About 1930, the tricarbocyanine dyes were synthesised almost simultaneously by three groups of workers, and their very powerful sensitising and ready accessibility made it possible to sensitise throughout the infra-red spectrum as far as $\lambda 11000 \mathrm{~A}$. Of the tricarbocyanines, the one having the furthest extension in the infra-red was xenocyanine, which is the tricarbocyanine from lepidine corresponding exactly to kryptocyanine, except that there are seven CH's in the chain and no less than thirteen CH's between the two nitrogen atoms, seven of them being in the chain and three in each of the nuclei. The maximum sensitising of xenocyanine is at $\lambda 9600 \mathrm{~A}$.

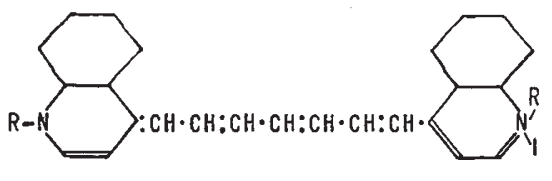

Xenocyanine.

Using tricarbocyanines, a great many very remarkable photographs have been taken by infra- 
red light. From aeroplanes, photographs can be taken which far exceed the range of the human eye, the record for distance still being held by that taken by Capt. A. W. Stevens in 1932 of Mount Shasta in California, the machine at the time flying over the Pacific 330 miles from Mount Shasta.

In addition to these long-distance photographs, of which many examples have been made during the last few years, photographs may be taken by infra-red light which is effectively invisible to the eye. So long ago as 1931, a photograph was taken of a large group of people who could see nothing whatever at the time, the room being lighted by tungsten lamps covered by filters of so great a depth that there was no visible light at all in the room. possible to prepare photographic plates of high sensitivity to any special region in the spectrum, and such plates are, naturally, of the greatest interest to scientific workers, and especially to astronomers and spectroscopists.

A few years ago, I classified the plates required for these purposes in order to reduce the mass of material to a system which would be available for the scientific worker. In the first place there are various types of photographic emulsions which are useful in scientific work and we must have some method of indicating these. The fastest type of emulsion was called Type 1, this having the disadvantage of a somewhat grainy structure and being of only moderate contrast. Type 2 is a somewhat slower emulsion of greater contrast and less graininess, while Type 3 is a fine grained

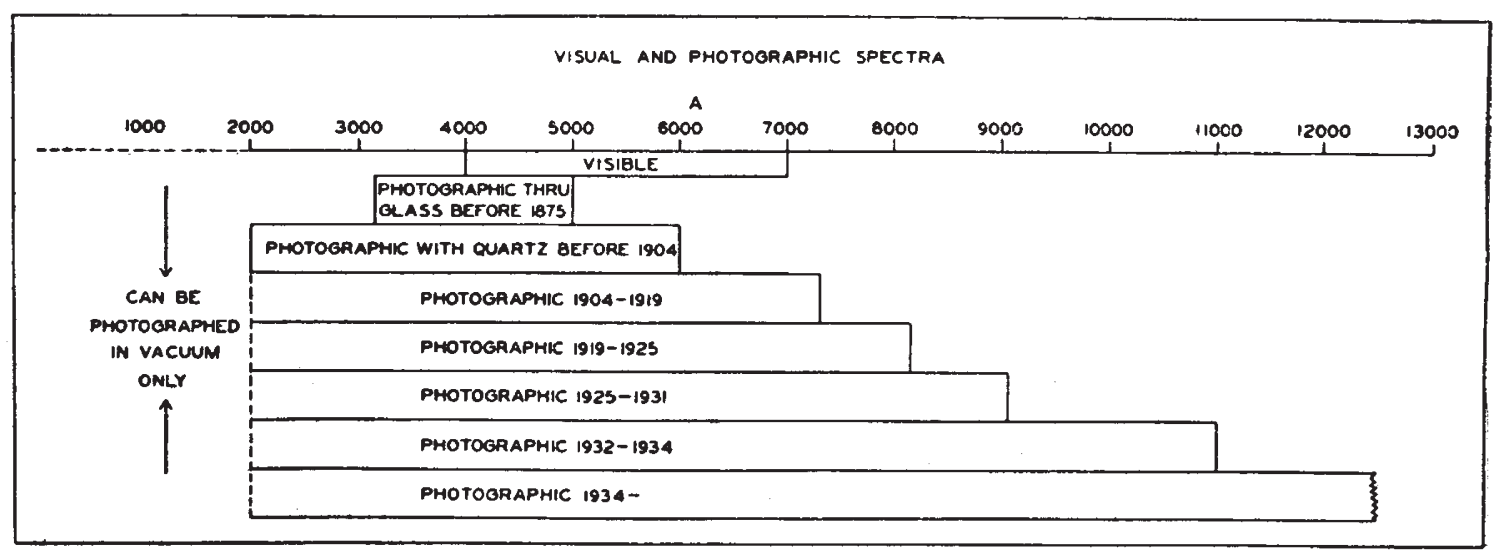

FrG. 1.

Within the last year, a still further extension of photography into the infra-red has become possible as a result of the development of tetra- and pentacarbocyanines. The method by which these longchain dyes are prepared is due largely to Dr. W. König of Dresden. In this synthesis the chain of carbon atoms is supplied by taking a compound of what is known as a 'di-anilide' type and allowing this to react with the quaternary salt of the base. Aniline is split out and the dye is formed. By an extension of this system, tetra- and penta-carbocyanines have been prepared, of which the latter has no less than eleven carbon atoms in the chain, and these dyes have proved to be excellent sensitisers for the far infra-red. With them, Dr. Meggers of the Bureau of Standards has recorded an argon line at $\lambda 13008 \mathrm{~A}$., and Dr. Babcock at Mount Wilson has photographed the solar spectrum to $\lambda$ 13000-14000 A.

There is thus a very wide range of cyanine dyes in which the absorption band and sensitising region ranges from extreme violet, or even ultraviolet in the case of such dyes as the oxacyanines, to a point in the infra-red approaching that where water vapour begins to absorb; this makes it emulsion of high contrast. Type 4 was of extreme contrast and still less speed, and Type 5 a very slow emulsion of extremely fine grain. Now these different types of emulsion can be sensitised for different parts of the visible and infra-red spectrum, and the different sensitisings are indicated by means of letters so that it is possible for an astronomer, for example, to decide that he could afford the exposure necessary for a Type 3 emulsion and that he wanted his maximum sensitivity in the orange with as high sensitivity as possible through the green but with no particular sensitivity in the red. Such a result is shown with the sensitising known as $D$, and the particular plate that he required would be classified as $3 D$.

The progress which the development of dyes has enabled us to make in the photography of the spectrum may be summed up in an approximate form in the accompanying chart (Fig. 1).

At the top of the chart is shown the visible spectrum and that portion of it which could be photographed on a collodion plate through glass apparatus before Vogel discovered the use of sensitising dyes. Vogel's discovery extended the 
photographic spectrum to $\lambda 6000 \mathrm{~A}$. The discovery of pinacyanol in 1904 extended the photographic spectrum to beyond $\lambda 7000 \mathrm{~A}$. The effect of dicyanine has been ignored in the construction of the chart, though for a few workers its use extended the photographic spectrum to beyond $\lambda 8000 \mathrm{~A}$. It was, however, only easy to reach that wave-length after the discovery of kryptocyanine in 1919, while the production of neocyanine in 1925 extended the range to $\lambda 9000 \mathrm{~A}$. Xenocyanine, made first in 1932 , enabled $\lambda 11000 \mathrm{~A}$. to be reached, and the pentacarbocyanine has now extended the photographic spectrum to beyond $\lambda 12000 \mathrm{~A}$.

\section{Coral Reefs of the Western Indian Ocean}

$\mathrm{T}^{\mathrm{H}}$ HREE papers recently published* conclude the reports on the intensive study of the reefs of the Western Indian Ocean that was carried out by the Percy Sladen Trust Expedition to the Indian Ocean in 1905. Such a study necessitated investigation along several lines, geological and geographical, as well as biological, for only by a judicious combination of this kind can one hope to solve such problems as: What are the foundations on which these reefs are built? How have they been formed, and what changes are taking place in them? How can the differences in the fauna of the different areas be explained?

Oceanographers and marine biologists are greatly handicapped by the inability of geologists to agree regarding the formation of the great oceans, and this is especially the case in the Indian Ocean, across which Gondwanaland, and, at a later period, the isthmus of Lemuria, are by some supposed to have connected India and Africa and to have formed the bases on which present reefs have been built. Others believe with Wegener that the oceans were formed by the drifting apart of the continents, such isolated fragments as the Seychelles being detached and left behind during the process.

At the present day we are woefully ignorant regarding the nature of the rock of the sea-floor, and in this connexion Dr. Wiseman's study of the basal rock of Providence Island is of particular interest, as it shows that this is volcanic in origin, and is probably of Eocene-Oligocene age. The southern end of the great Seychelles Bank is volcanic, and the recent work of the John Murray Expedition has shown that the Carlsberg Ridge is, at least in part, also volcanic in structure. This raises the question whether all these areas may not have been formed simultaneously in the Eocene-Oligocene period as part of a widespread disturbance in East Africa, and perhaps con-

* Proc. Linn. Soc., 1936. Reports of the Percy Sladen Trust Expedition to the Indian Ocean, 1905. The Reefs of the Western Indian Ocean. I. Chagos Archipelago. II. The Mascarene Region. By Prof. dredged from a depth of 744 Petrography and Signiflcance of a Rock dredged from a depth of 744 fathoms, near to Providence Reef, Indian Ocean. By Dr. J. D. H. Wiseman. Concluding Remarks on the DistriTemperature Observations. By Prof. J. Stanley Gardiner. temporaneously with the curved ridges of the Malay Archipelago. Whatever the origin of these foundations, many of them are to-day covered with coral reefs or atolls, and Prof. Stanley Gardiner has concluded that these are probably of recent origin, perhaps only some 10,000 years old, while as recently as 3,500 years ago a worldwide recession of the sea-level caused the exposure of the reefs and the formation of islands. From the very outset, conditions appear to have been different in the various regions. In the Mascarene Region no atolls were ever formed and the coral reefs are now being cut back, leaving wide banks that extend for considerable distances beyond the reefs, as a result of a change that was probably world-wide, since similar conditions are to be found in the reefs of the southern part of the Pacific Ocean. In the Maldive and Chagos Archipelagoes, atolls were formed, but the islands and reefs are now being eroded away, though at different rates, so that while the Maldives are still in a comparatively stable condition, the Chagos group is composed mainly of submerged banks, the relics of former surface structures.

We are still uncertain as to the actual mode of formation of the reef and especially of the reefrock that enables the reef to withstand the pounding of the seas, but Stanley Gardiner attributes this largely to the growth of Lithothamnionex"no bank reaches the surface to form a reef unless covered by Lithothamnioneæ"-the upgrowing corals being firmly cemented together and converted into a reef by Lithophyllum. Thus any condition that may be detrimental to the growth of this alga would prevent the full development of the reef or, where such had been formed, its present maintenance; hence the necessity of a careful study both of the sea-water itself and of meteorological and other conditions.

Great differences are to be found in the fauna of the areas studied. The Seychelles appear to be inhabited by the remains of a fauna and flora of long standing, and this is explained by the erosion of a larger area into the smaller islands of the present time. The reef-fauna of the Maldive, 